\title{
MONTAGE AS SPATIAL RECONSTRUCTION OPERATION METHOD IN DESIGNING CINEMATIC ARCHITECTURE
}

\author{
Neneng Rika Lestari ${ }^{1}$ ) Kristanti Dewi Paramita ${ }^{2 *}$ ) Paramita Atmodiwirjo ${ }^{2 *}$ ) \\ *)Corresponding author email : kristanti.dewi@ui.ac.id, paramita@eng.ui.ac.id
}

1) Student of Department of Architecture, University of Indonesia, West Java, Depok 16424, Indonesia

2) Lecturer of Department of Architecture, University of Indonesia, West Java, Depok 16424, Indonesia

\author{
Article info \\ MODUL vol 21 no 2, issues period 2021 \\ Doi : :10.14710/mdl.21.2.2021.142-154 \\ Received : 14 desember 2021 \\ Revised : 20 desember 2021 \\ Accepted : 30 desember 2021
}

\begin{abstract}
This article investigates montage to develop cinematic architecture through operations of spatial reconstruction that present a sequence of spatial experiences. Montage is a part of discourses related to cinematic, film, and architecture. This article explored the montage approach as the primary basis in the architectural design process through spatial experience. The discussion is based on the idea that a form of montage emphasizes three things, i.e., sequence, multiple layers of meaning, and movement. These three aspects were further observed through the montage precedent comprising various cinematic precedents based on montage in architecture, i.e., Manhattan Transcripts and Parc de La Villette from Bernard Tschumi, Villa Savoye from Le Corbusier, and Maison Bordeaux from Rem Koolhaas. The finding of this precedents study suggests an understanding of space reconstruction operations, i.e., dismantlement, disappearance, and reassembly. All of these three exist as strategies that will be part of the production process to develop montage-based cinematic architectural design, creating new spatial sequence that provide alternative spatial experience. Exploration on montages and its design mechanisms expands the knowledge regarding cinematic-based architectural design.
\end{abstract}

Keywords: Montage; Cinematic; Film; Architecture; Spatial Reconstruction Operations.

Neneng Rika Lestari, Kristanti Dewi Paramita, Paramita Atmodiwirjo

\section{INTRODUCTION}

This article aimed to understand more deeply about montages in cinematic architecture and how it generates operations of spatial reconstruction. Montage is a part of discourses shaping cinematic qualities of an architectural space (Koeck, 2013). Montage is important as an architectural approach since montage enable a form of editing within the design process. Montage is important to be explored since it generates sequence (Eisenstein, Bois, \& Glenny, 1989), which then define montage as space sequence editing. Penz (2018) revealed that the cinematic is a spatial practice. That is, the audience obtain a similar sense of being spatially as in the screen. Therefore, space of cinematic may affect the audience's emotions, imagination, and memory (Pallasmaa, 2007). Theories related to film, film editing, and cinema have permeated the process and articulation of architectural and urban design (Koeck, 2013). In this case, the production of film and cinematic space are interrelated. Frunza (2007) emphasized that designing a film driven by architectural theories and practices can be referred as 'cinematic.' The cinematic is an art of combining time, movements, and changes. Theory and practices can be simultaneously and transformatively engaged along with an expanded and enriched reading of design aspects (Paramita, 2021). The cinematic space's ability to overcome changes leads architects to use film to support the space exploration process (Vidler, 2000). Hence, filmmakers arguably demonstrate similar role as architects, creating a space (Till, 1996). "When talking about cinema [...] be the path followed by the mind across a multiplicity of phenomena, far apart in time and space, gathered in a certain sequence into a single meaningful concept" (Eisenstein et al., 1989, p. 116). Under Eisenstein's notion, it can be understood that the architectural building users do not experience the entire building in one single time. Conversely, they travel from one room to another or from frame to frame, creating a specific sequence. Using a film as a form of an architectural instrument enables 
the designer to redefine the idea of user perception and viewpoint in experiencing space.

The discussion of film and architecture proposes cinematic approach as the basis of developing the architectural design process. A film is a time-related medium (Vidler, 2000). Based on Vidler's idea, it can be understood that time creates changes that continuously develop the film story. Time is crucial in creating a space, as time can state the spatial condition change during a particular period following human movements. Consideration of the time element allows us to calculate the ever-changing human activity needs in the design process. Rattenburry (1994) argued that a film is a manipulation outcome from real existence (realism). A film is an exploration and information delivery medium. The information is stated in a spatial form to deliver ideas and viewpoints of the filmmaker. Following Rattenburry and Vidler's explanation, it can be concluded that film and architecture share a real and representational space. However, they retain narratives related to the time and space in the scenario. In this case, architecture assembles spaces, while film constructs the scenarios to observe those spaces in time. A film is also connected with the actor, allowing an engaging relationship with spatial users in reality.

The filmmaking process provide new parameters as part of the architectural design process, namely narrative as a conceptual element in the initial design step, mise-en-scene as framing in decision making, and montage as the final process, and design editing in changing the existing frame or shot (Koeck, 2013; Prince \& Hensley, 1992; Tobe, 2017). Spatial experience is also related to the idea of interiority of the structure in relation to the public to the public sphere (Teston, 2020). The cinematic elements demonstrates urban interior settings' role in providing multiple narratives on social issues (Atmodiwirjo \& Yatmo, 2021).

Montage in cinema is a form of design editing which changes the existing frame or shot. As an architecture exploration, further discussion will define this form of design editing process as operations of spatial reconstruction. With a montage approach, the study focuses on its narrative and mise-en-scene aspects, which resulting in the sequence of changes, time, and movement in space (Frunza, 2007). The sequence creates a continuous change of environment and thereby produces a fluid space (Böck, 2015). Using montage as an architectural approach allows designers to produce sequences that make a more fluid relationships between spaces, so users may experience different spatial experiences each time they are in that space. Fluidity of space may further contribute towards a sustainable environment by a particular material consideration to the design (Gutai, 2015), which becomes the contribution of architectural montage approach.

This article aims to create a cinematic architectural space through an architectural montage approach, generating operations of spatial reconstruction to present a sequence of spatial experiences. This article uses precedent to investigate deeper into montages in architecture. The study result is based on such reading towards cinematic precedents, concluding in finding the operations of spatial reconstruction.

\section{LITERATURE STUDY}

\section{Montage as a Cinematic Architectural Approach}

As discussed in the previous explanation, montage is one of the approaches to construct the architectural space in cinematic architecture. In designing a cinematic architectural space, a montage is a relevant approach to understanding and arranging cinematic architectural space. Allen (2009) states that montage is a design construction process using instrumental procedures. In this study, montage uses operations of spatial reconstruction which generate a new sequence of spaces to build the relationship between one picture and another (from one space to another) (pp. 28-30). Interesting analogy between filmmaker and architect, in the sense that both are essentially builders (Koeck, 2013). The montage approach exists in various architectural comprehension. The following paragraphs will explore ideas in montage comprehension from Kullesov, Deriu, and Eisenstein (Deriu, 2007; Eisenstein et al., 1989; Prince \& Hensley, 1992).

Montage in architecture, according to Kullesov (1992), is a "montage to uncovering the rules and principles of shot" (p. 60). It indicates that spatial sequences are important since the montage principle is the reference in editing existing shots, allowing separation, reconstruction, and the remaking of cinematic materials (Prince \& Hensley, 1992). It can understand that changing shots will change the overall sequence's meaning. Therefore, audience or user viewpoints will change when the shots are being changed. The said shot is defined as an architectural element. Following Deriu's notion on architectural montage, it can be defined that multiple layers of meaning as crucial, since Deriu utilized these layers to show that each layer has meaning as an implicit modus operandi of architectural montage. The multiple layers are assemblage, elevation, cinematism, exposition (Deriu, 2007). Eisenstein (1989) defined architectural montage by arguing, "I would only ask you to look at it with the eye of a filmmaker: it is hard to imagine a montage sequence for an architectural ensemble more subtly composed, shot by shot. Then the one that our legs create by walking among the buildings of the 
Acropolis" (p. 117). It can be understood that sequences from consecutive shots create architectural paths requiring human movements to cross the overall site. The idea introduced by Eisenstein is that movements creating architectural paths are essential to deepening the overall sequence in the site. Based on the understanding of Kullesov, Deriu, and Eisenstein's ideas, three things are emphasized in the idea of developing architectural montages, which consist of sequence, layers of meaning, and movement. These three aspects are further inspected through architectural precedents to understand montage as spatial reconstruction operations. Spatial reconstruction operation will be discussed further.

\section{MATERIAL AND METHOD}

This study presents a study on architectural montage approach in designing cinematic architectural space through operations of spatial reconstruction. The study is done by analyzing various cinematic precedents based on montage in architecture, i.e., Manhattan Transcripts and Parc de La Villette from Bernard Tschumi, Villa Savoye from Le Corbusier, and Maison Bordeaux from Rem Koolhaas/OMA. These four precedents are crucial to observe since they are often part of the cinematic discourse in architecture. Also, each precedent has an engaging cinematic quality in the form, representation, or in the design process. An example is Manhattan Transcript, whose product is not a building but the cinematic design process can be studied into its architecture. Another example is Parc de La Villette, whose design process is also related to the celebration of firework to be carried out in the park. The cinematic quality of Villa Savoye and Maison Bordeaux is related to the promenade architecture, emphasizing the movement that occurs in the building. Analyzing the four precedents was performed by dismantling each precedent's design process and mechanism. This precedent study resulted in a synthesis of the design process and montage mechanism that will serve as the basis for further composing cinematic architecture with a montage approach.

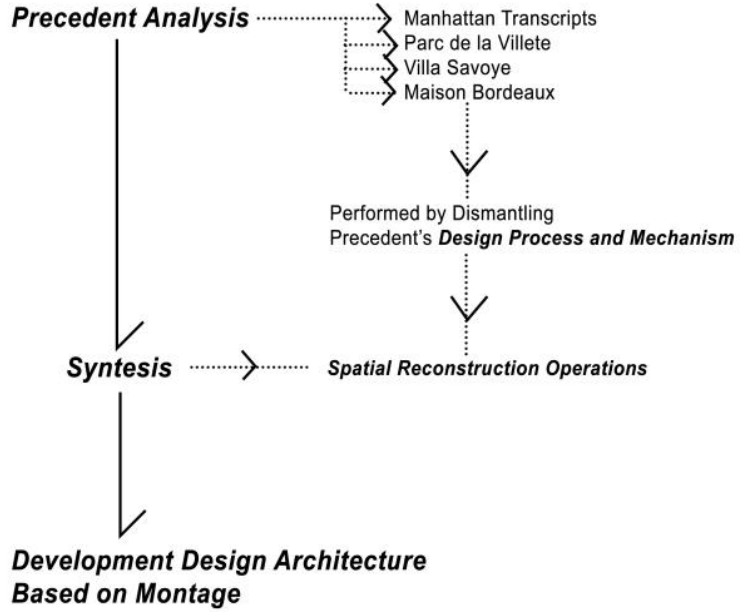

Figure 1. Flow of Analysis Cinematic Architecture Based on Montage.

\section{RESULT AND DISCUSSION \\ Architectural Montage Precedent Analysis}

This section will investigate some of the precedents that arguably may inform methods of architectural montages through their projects, i.e., the Manhattan Transcript and Parc de La Villette from Bernard Tschumi, Villa Savoye of Le Corbusier, and Maison Bordeaux from Rem Koolhaas. The study explore three aspects of montage, i.e., sequence, layers of meaning, and movement, through the design process and the mechanism of these four precedents, which will be concluded as the basis for designing cinematic architecture through a montage approach.

\section{Manhattan Transcripts - Bernard Tschumi}

In Figure 2, it can be explained that Manhattan Transcripts is a theoretical project of Bernard Tschumi, regulated in four elements, i.e., park, road, tower, block (Tschumi, 1981). It can be analyzed that Tschumi initiates this project by reading spatial in Manhattan City through the Manhattan Transcript, which acts as a spatial representation or object. Tschumi (1981) categorizes his experiences against Manhattan City in three layers and studies these layers separately. Tschumi separates (disjunct) his spatial experiences into episodes. Each episode has three sequences, i.e., object, event, and movement. The statement defines the process of disjunction as a montage operation regarding the development of multiple layers of meaning, in which movements, events, and layers of objects are separated into sequence episodes. This separation will then become the basis of the design process through a montage approach. Objects consist of buildings arranged from the map, layout, and pictures; movements are arranged from choreography, exercise, or other moving diagrams, while events are arranged from newspaper 
pictures (Tschumi, 1981). In the statement, it is understood that movements, events, and objects are the leading elements of the observation process in montage operations. These movements, events and objects can be categorized through catalog drawings, creating a frame to investigate some particular information (Karimah \& Atmodiwirjo, 2021).

As mentioned earlier, three things are emphasized in montage comprehension, one of which is movement. Therefore, movement is crucial in creating the episode sequences. Manhattan Transcripts eliminates all trivial matters for urban architecture. Object, movement, and event are necessary fragments to outline the overall structure, generating a new spatial structure (Tschumi, 1981). This elimination process is defined as the montage operation related to eliminating multiple layers of meaning, i.e., movement, event, and object. This elimination process deletes unnecessary things to generate new sequence development. According to Degenhart, Tschumi objects to the fusion of shapes and programs or reduction of something into another (Dagenhart, 1989). From the statement, it is understood that Manhattan Transcript does not produce a product in the form of a building, so the process of designing the montage only ends in the process of elimination without reassembly until it becomes the shape of the building.

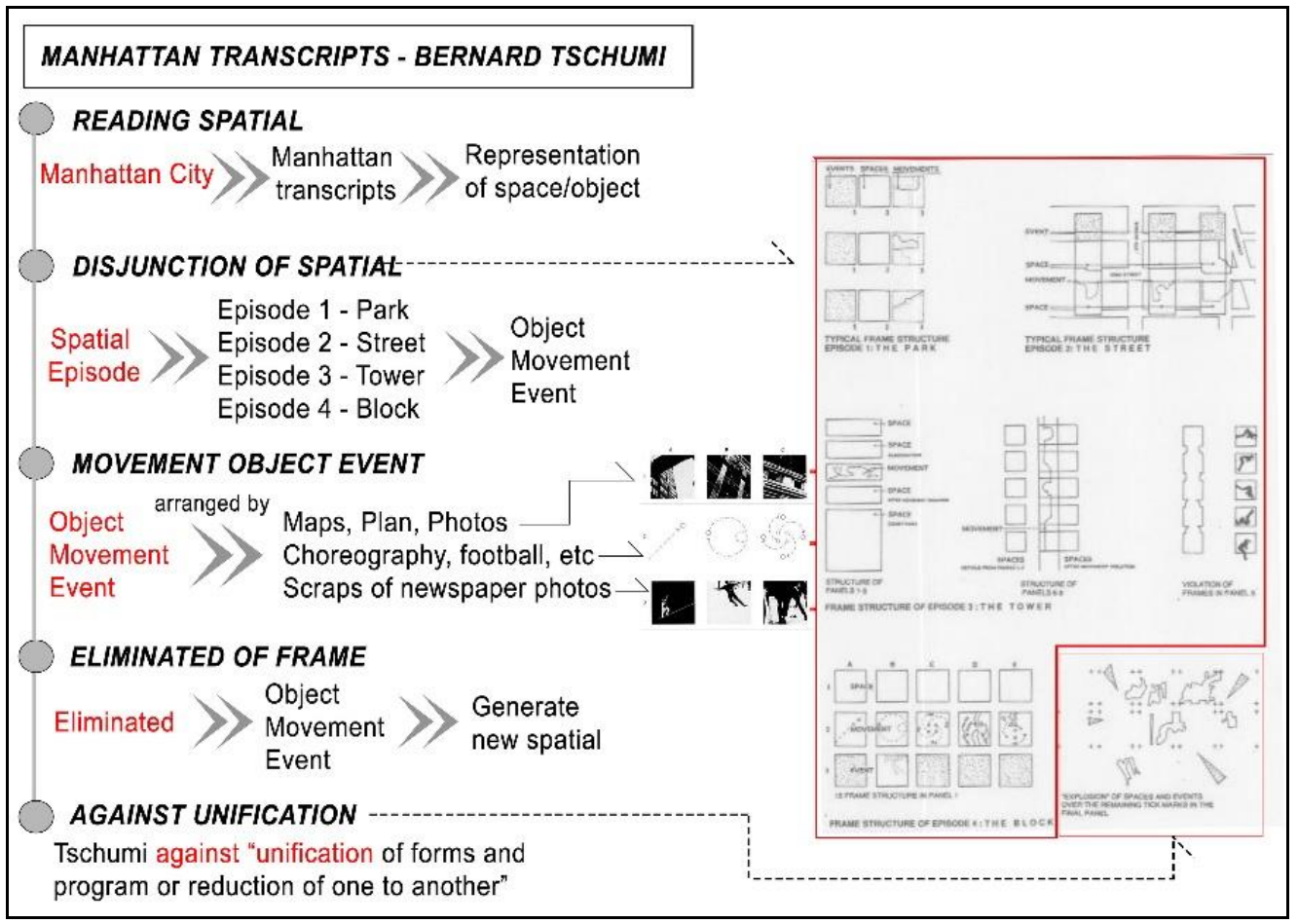

Figure 2. Analysis of Precedents Manhattan Transcripts

\section{Parc De La Villette - Bernard Tschumi}

In Figure 3, it can be explained that the Parc de La Villette project aimed to create a new model for the urban park (Costanzo, 2009). The Parc de la Villette encourages spatial continuity and the circulation of the visitors (Böck, 2015). It is understood that Tschumi initiated his design by reading spatial in a park, aiming to enable visitors to explore, move, and interact. Therefore, Tschumi focuses on the experience of the park spaces. Tschumi arguably considers event, movement, and object as the primary concept and handles each layer separately, as in the Manhattan Transcript.
In Figure 3, The line is defined as movement, a linear structure. Point is a system to regulate and design an event. Movements and events, along with their notation, which is an investigation into the nature of architecture. Meanwhile, the surface is defined as spatial/object territories, green open space, and furniture (Tschumi, 1987). In this notion, it can be understood that the separation of layer process is the development of multiple layers of meaning in montage operations. The layers, i.e., line, point, and surface, are separated to be observed deeper in the montage operation. Based on the Parc de La Villette diagram, this project utilized fragments that are being analyzed, designed, and reunited to create a final product. Hence, the reassembly 
process is a montage operation in the reunion to create new sequences.

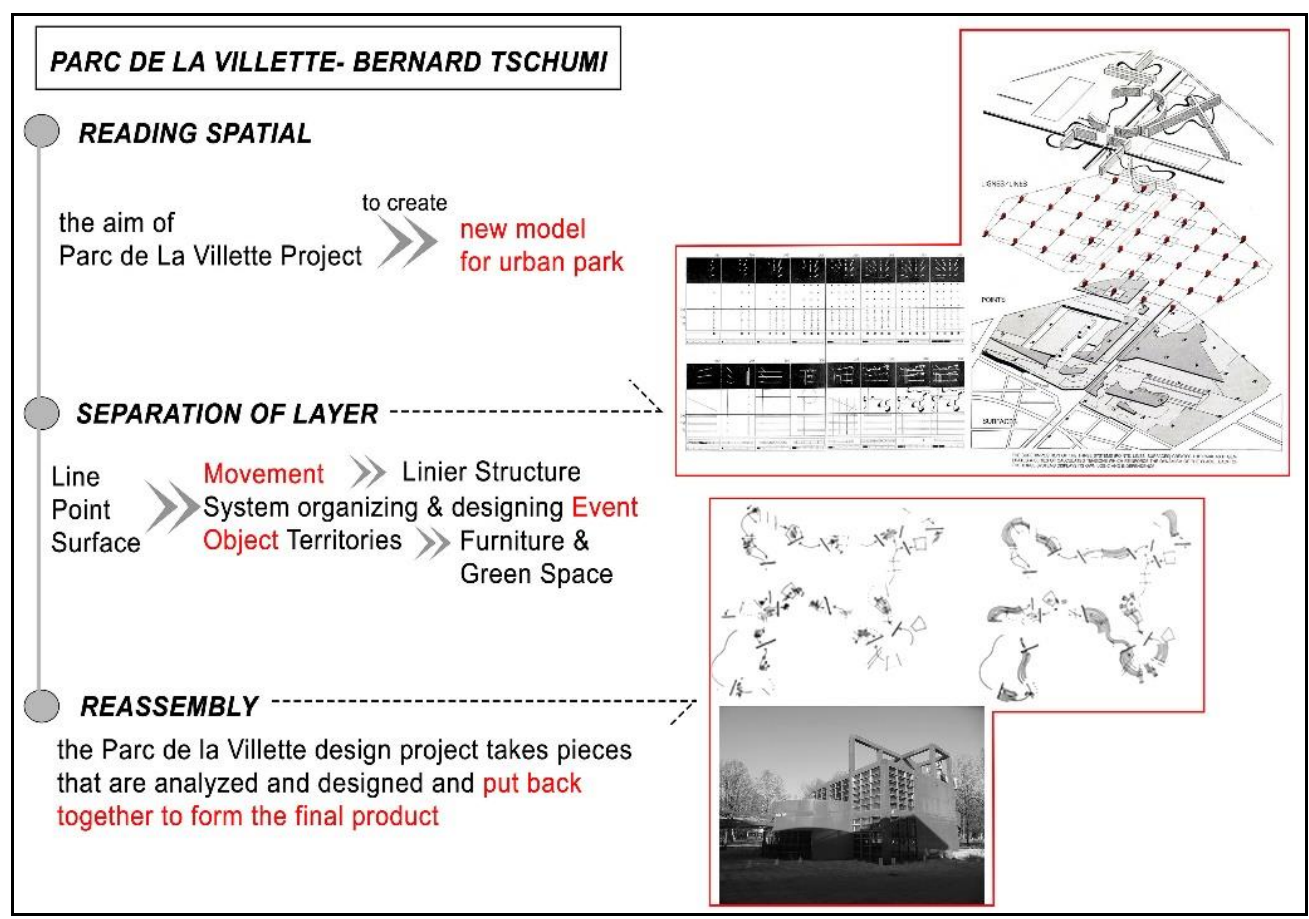

Figure 3. Analysis of Precedents Parc De La Villette

\section{Villa Savoye - Le Corbusier}

In Figure 4, it can be explained that Le Corbusier constantly asserted that the house was a machine for living. There is no doubt that the machine also became the generating element in Le Corbusier's architecture (Carranza, 1994). It is understood that in initiating a cinematic design process based on montage, Le Corbusier applies reading the context to develop sequences from its mechanical concept. Villa Savoye is a house designed by following an architectural promenade, where the promenade emphasizes the experiences in movements through spaces. An architectural promenade exists when users gradually pass buildings. Sequences continuously create environmental changes; hence, generating a flowing space when users explore it. It is a narrative instrument that explores architectural events (Böck, 2015). This statement observes that movements and events are the development of several layers of meaning, in which movements and layers of events can produce spatial sequences in montage operations. As mentioned earlier that Le Corbusier is famous for his statement, "A house is a machine to live" (Carranza, 1994, p. 75). It is translated into the assembly line design. Le Corbusier illustrates a ramp sequence moving from a lower level to the top tier, forcing the inhabitants to move across spaces (Böck, 2015). In this assembly process, it can be concluded that Le Corbusier unites the assembly lines through movement and event layers, creating a sequence to generate montage operations. 


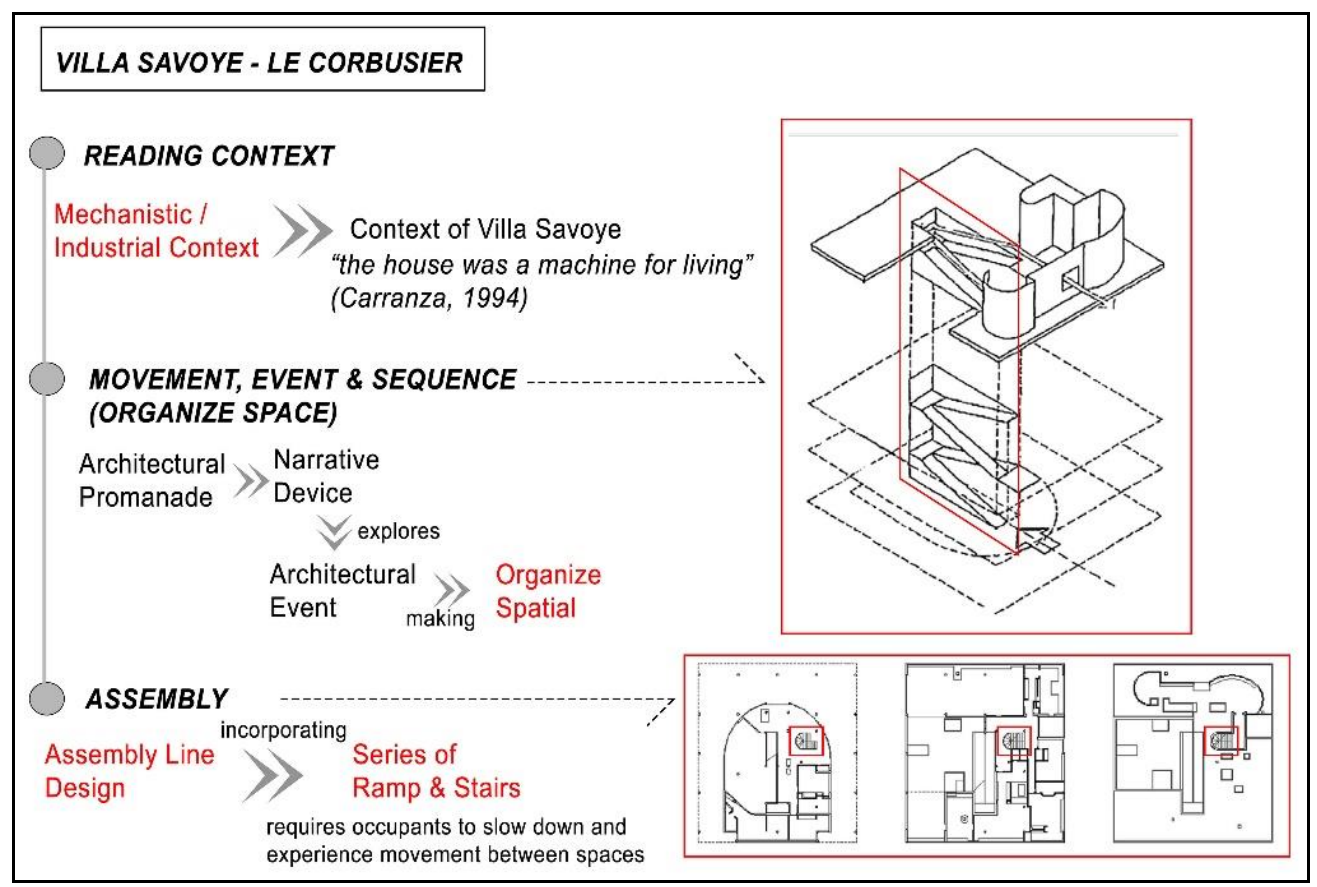

Figure 4. Analysis of Precedents Villa Savoye

\section{Maison Bordeaux - Rem Koolhaas / OMA}

In Figure 5, it can be explained that Koolhaas started its montage design process by highlighting existing conditions of nearly damaged utilities in his client's house. Such utilities will be later reconfigured as moving platform lift in his client, Maison Bordeaux's, house (Böck, 2015). From the explanation, it can be understood that Koolhaas started his montage-based cinematic design by the apply reading spatial/context in nearly damaged functions, i.e., platform lift. This platform lift becomes the central theme in the montage operation, articulating the vertical circulation of the project. In Maison Bordeaux, Koolhaas cautiously designs an observation path, resembling the promenade strategy in Villa Savoye Le Corbusier (Böck, 2015). It can be analyzed that movement and passage are crucial in developing multiple layers of meaning, that the movement and passage elements are observation elements generating new sequences in its montage process.

In Figure 5, it can be explained that Koolhaas proposed two leading defense lines in the Maison
Bordeaux design process, i.e., dismantlement and disappearance. Dismantlement and disappearance are key strategies for 'architecture that engineer unpredictable things' (Böck, 2015). Unpredictable things may be seen in the existing conditions of almost damaged lift services as found from Maison Bordeaux, which then redefined and edited as the movable lift platform (see Figure 5). It can be analyzed that dismantlement is the sequence development of montage operations, which is the process that aims to dismantle layers such as movement and passage in the platform lift system and eliminate trivial matters to simulate new sequences. Then, Koolhaas rearranged and combined them with his ideas (Böck, 2015). This reassemble process is the development of a montage operating sequence, in which Koolhaas reassembles those that have been dismantled and disappeared, resulting in a new sequence. Koolhaas project redefined Maison Bordeaux by creating re-interpretation of the promenade architecture, generating rearrangements of its spatial parts in a new context (Böck, 2015). These displacement and interpreting processes are Koolhaas's final montage operation process to Maison Bordeaux. 


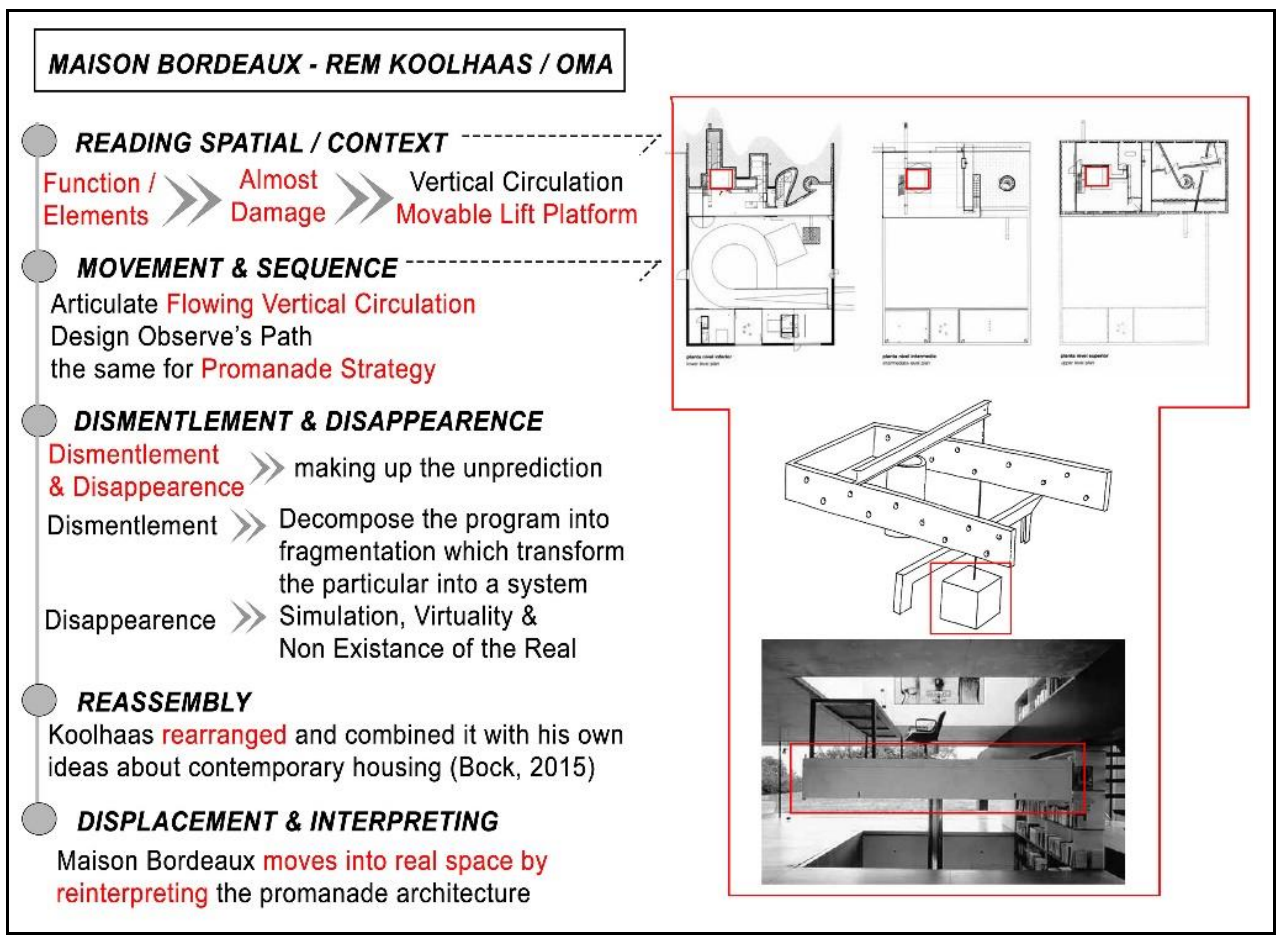

Figure 5. Analysis of Precedents Maison Bordeaux

\section{Analysis Results of Montage Process on} Architectural Precedents

This section presents the analysis results of the Manhattan Transcript, Parc de La Villette, Villa Savoye, and Maison Bordeaux precedents studies, concluding how these precedents may inform application of the montage process in their design. It can be explained that Manhattan Transcripts initiated its design process by reading space, as cam be seen in the way Tschumi observes the spatial and context of Manhattan city to be programmed in the design. The following process is the disjunction of spatial, in which Tschumi applies a separation process to separate spatial/context to be produced in the design. The next process is eliminated through the frame, in which Tschumi eliminates trivial elements in the context. Subsequently, against unification in Manhattan Transcripts, Manhattan Transcripts does not produce a product in the form of a building, so designing the montage only ends in the process of elimination without reassembly until it becomes the shape of the building. Hence, its reassembly process does not need to go into the diagram analysis process. Similarly, Parc de La Villette also started the process by reading spatial through the park, in which Tschumi observed/scrutinized spatial and context to be programmed in the design. However, Tschumi followed by creating a spatial disjunction, in which Tschumi applies a separation process to separate spatial/context to be produced. The next process is reassembly, in which Tschumi reassemble previous separation to generate the final product.

Villa Savoye started the process through the reading spatial, in which Le Corbusier observed or scrutinized spatial and context to be programmed in the design. The following process is assembly, in which Le Corbusier applies an assembly process on the context to be produced, generating a final product. Maison Bordeaux initiated the design process by reading spatial on the lift platform, which Koolhaas/OMA observed and examined the context to be programmed in Le Corbusier's design. The subsequent process is dismantlement, in which Koolhaas/OMA applies a dismantlement process to dismantle spatial/context to be produced. Then, disappearance aims to eliminate trivial elements in the context. It is followed by reassembly, which Koolhaas/OMA reassembly of the previous separation. Next, displacement and interpreting, to which Koolhaas/OMA transfers and interprets or rearranges the new context. Movement, event, object, and sequences are parts or elements determining the production process and montage-based design. The following is the analysis results of the montage process on several architectural precedents. Based on the results of previous precedents, Tschumi's understandable interpretation of the precedents of the Manhattan Transcripts and Parc de La Villette attaches importance to the transformation of the separation of space Neneng Rika Lestari, Kristanti Dewi Paramita, Paramita Atmodiwirjo 
experiences into episodes as montages. Meanwhile, Le Corbusier's understandable interpretation of the precedents of Villa Savoye and Rem Koolhaas/OMA on the precedent of the Maison Bordeaux attaches importance to the promenade architecture that forms a spatial arrangement that is read as a series between layers on a montage.

From the above articulation of the precedents' design mechanism, the following section discusses how such precedents generate a new method of the architectural montage approach, which emphasizes spatial experience. Through montage approach, the spatial experience becomes the main goal in producing new sequences of a cinematic architectural design. The following section explore how montage mechanisms construct the spatial production process, focusing on the dismantlement, disappearance, and reassembly processes. These mechanism organises movements, events, objects, and sequences as elements that generates a montage-based production/design process through operations of spatial reconstruction.

\section{Operations of Spatial Reconstruction Based on Montage}

As mentioned in the previous discussion, montage mechanisms consist of operations of spatial reconstruction which consist of dismantlement, disappearance, and reassembly to generate new sequences of spatial experience. The reading spatial or context is an observation process, which begins by annotating several elements of space that generate multiple layers of meaning to determine the following design process, i.e., production process. As found in the precedent study, elements of multiple layers of meaning to be observed may consist of event, movement, and object. The observed events were selected first to reconstruct cinematic architectural space through dismantlement, disappearance, and reassembly to produce new space sequences. Costanzo (2009) revealed that form-concepts are formed from putting together a complexity that includes materials, movements, and programs in the definition of architectural forms (Costanzo, 2009). It can be understood that form can be composed of material that can be interpreted as objects, then composed of movement, and then programs that are interpreted as event. Objects, movements, and programs are used as tools in performing the dismantlement, disappearance, and reassembly operations. The following passages explain each operation and their corresponding strategies to be used to generate montagebased spatial sequence.

\section{Dismantlement Operation}

Dismantlement is an initial spatial production process in the operation of spatial reconstruction based on montage approach. Dismantlement is performed by dismantling elements, i.e., event, movement, and object, separated in particular conditions. The grouping of strategies conducts dismantlement and separation. This grouping is informed by Tschumi's Manhattan Transcripts, which grouped parts of the park, street, tower, and block (Tschumi, 1981). Such form of grouping as dismantlement strategy can also be found in Koolhas articulation that "the method of dismantlement is not a generative tool to rethink the design process [...] yet his strategy of hybridization, proximities, frictions, overlaps, and superpositions.” (Böck, 2015, p. 154). The statement can be understood as in order to carry out demolition or separation, some of the relevant grouping strategies that can be performed are done through hybridization, proximities, frictions, overlaps, and superpositions. These strategies facilitate the production process to discover each event, movement, and object required to support the users' spatial needs.

In the operations of spatial reconstruction, dismantlement is relevant to new sequences of space. Such sequences should be dismantled or separated from the elements of multiple layers to generate other possibilities. Therefore, it can develop cinematic architectural design emphasizing spatial experience. As stated by Allen, that montage is revealed construction (Allen, 2009). Construction with interval shows that in a montage is not as significant elements, but the space in between that defines the potential depth. Interval space is a shallow and compressed space relating to time and linked together by the observer's perception and memory. Construction with interval recognizes the discontinuities built into the fabric of time and space. Montage, on the other hand, works with surfaces. These surfaces imply a new kind of space (Allen, 2009). From the idea, it can be understood that producing a montagebased construction will be show interval, discontinuity, and surface that becomes the basis for producing sequences in spatial experience through dismantlement operations by trying to propose possibilities concerning the operations of spatial reconstruction based on the montage approach. Dismantlement is applied by detailing changes in each element. This can be seen in the following diagram. 


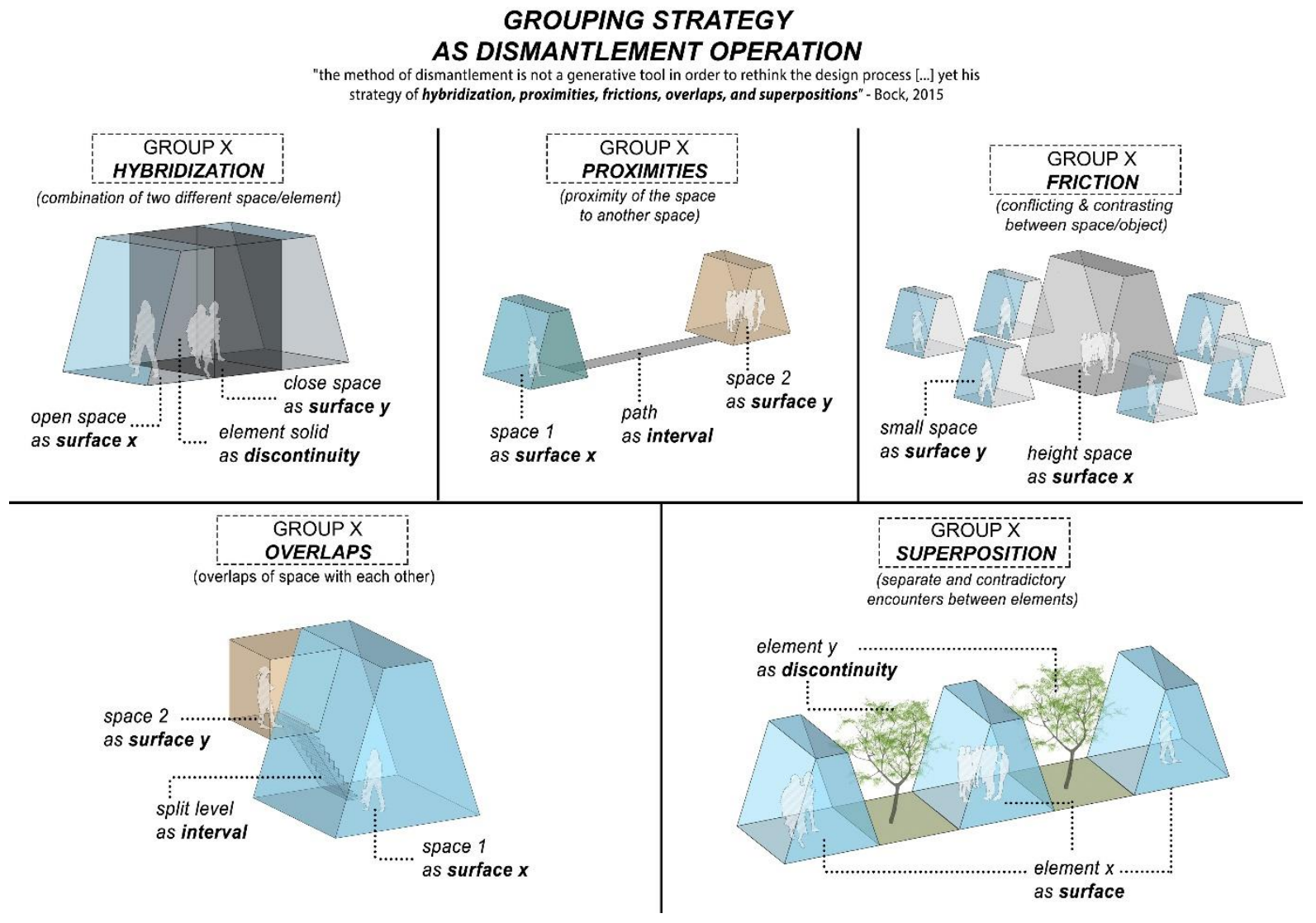

Figure 6. Dismantlement Operation

As explained earlier, the grouping strategy is carried out by separating the five strategies: hybridization, proximities, frictions, overlaps, and superpositions. Based on Figure 6, it can be explained that grouping of hybridization is done by combining two elements in unity. In Figure 6 on the hybridization section, for example, open space as surface $\mathrm{x}$ and closed space as surface $y$, in the merger, then comes a solid element as a discontinuity that is used as a transition between surfaces. The presence of discontinuity impacts the spatial experience of objects observed by users. Based on Figure 6, the grouping of proximities is done by grouping the proximity of space to each other. In Figure 6 on the proximities section, for example, space 1 as surface $x$ and space 2 as surface $y$, by looking at the proximity of two surfaces, then comes the path as an interval that becomes the distance among them. The presence of this path impacts spatial experiences on movements that the user will trace. Based on Figure 6, grouping friction is done by grouping spaces with conflicts and contrasts with others. In Figure 6 on the friction section, for example, there is height space as surface $\mathrm{x}$ surrounded by small space as surface $\mathrm{y}$. The two surfaces contrast with each other to impact the spatial experience of the object observed by the user. Based on Figure 6, the grouping of overlaps is done by grouping the overlaps of space to each other. In Figure 6 on the overlaps section, for example, space 1 as surface $\mathrm{x}$ and space 2 as surface $\mathrm{y}$, by looking at the overlapping of two surfaces, then comes split levels as inverse between surface $x$ and surface $y$. The presence of this split level has an impact on spatial experience on movement that the user will trace. Based on Figure 6, the grouping of superposition is done by separate and contradictory encounters between elements. Figure 6 on the superposition section, for example, element $\mathrm{x}$ as a surface, because to bring together the two opposite elements, then element $y$ as discontinuity. Two elements as surface and discontinuity, are at odds with each other so that it will impact spatial experience on the object observed and the movements traced by the user. The operation of the dismantlement depends on the event observed, for example, film/movie, dance performance, or other events that utilize the potential in spatial elements. So, each event selected will be different in

Neneng Rika Lestari, Kristanti Dewi Paramita, Paramita Atmodiwirjo 
understanding the surface, interval, and discontinuity in the event.

\section{Disappearance Operations}

Next, disappearance is the subsequent spatial production process the operation of spatial reconstruction based on montage. Disappearance is done by disguising elements such as event, movement, and object. The disappearance strategy was carried out as in the precedent in which Koolhaas emphasized that "...the strategy of disappearance does not use disassembly for the subsequent reorganization of the whole into a new entity but aims at simulation, virtuality, and nonexistence of the real." (Böck, 2015, p. 152). The statement can be understood that the disappearance strategy is carried out disguised on the camouflage strategy through simulation, virtuality, and nonexistence of the real. Ken Smith reveals that there are 4 strategies in camouflage i.e., deception, confusion, imitation, and decoy (Amidon, Rappaport, \& Reed,
2006). It can be attributed that simulation and imitation both copy something else. Virtuality and decoy are both used as bait to cover things behind them. In the operations of spatial reconstruction, the disappearance is relevant to new sequences of space. These sequences disguise the elements of multiple layers to generate other possibilities. Hence, it can develop the cinematic architectural design focusing on spatial experience. As stated by Allen, that montage is revealed construction that to produce a montage-based construction will be shows interval, discontinuity, and surface (Allen, 2009). It will be the basis for producing sequences in spatial experience through disappearance operations by trying to recommend possibilities regarding operations of spatial reconstruction based on the montage approach. Disappearance is applied by creating transformation details in each element. This can be seen in the following diagram.

\section{CAMOUFLAGING STRATEGY} AS DISAPPEARANCE OPERATION

...the strategy of disappearance does not use disassembly for the subsequent reorganization of the whole into a new entity but aims at simulation, virtuality, and non existance of the real" - Bock, 2015

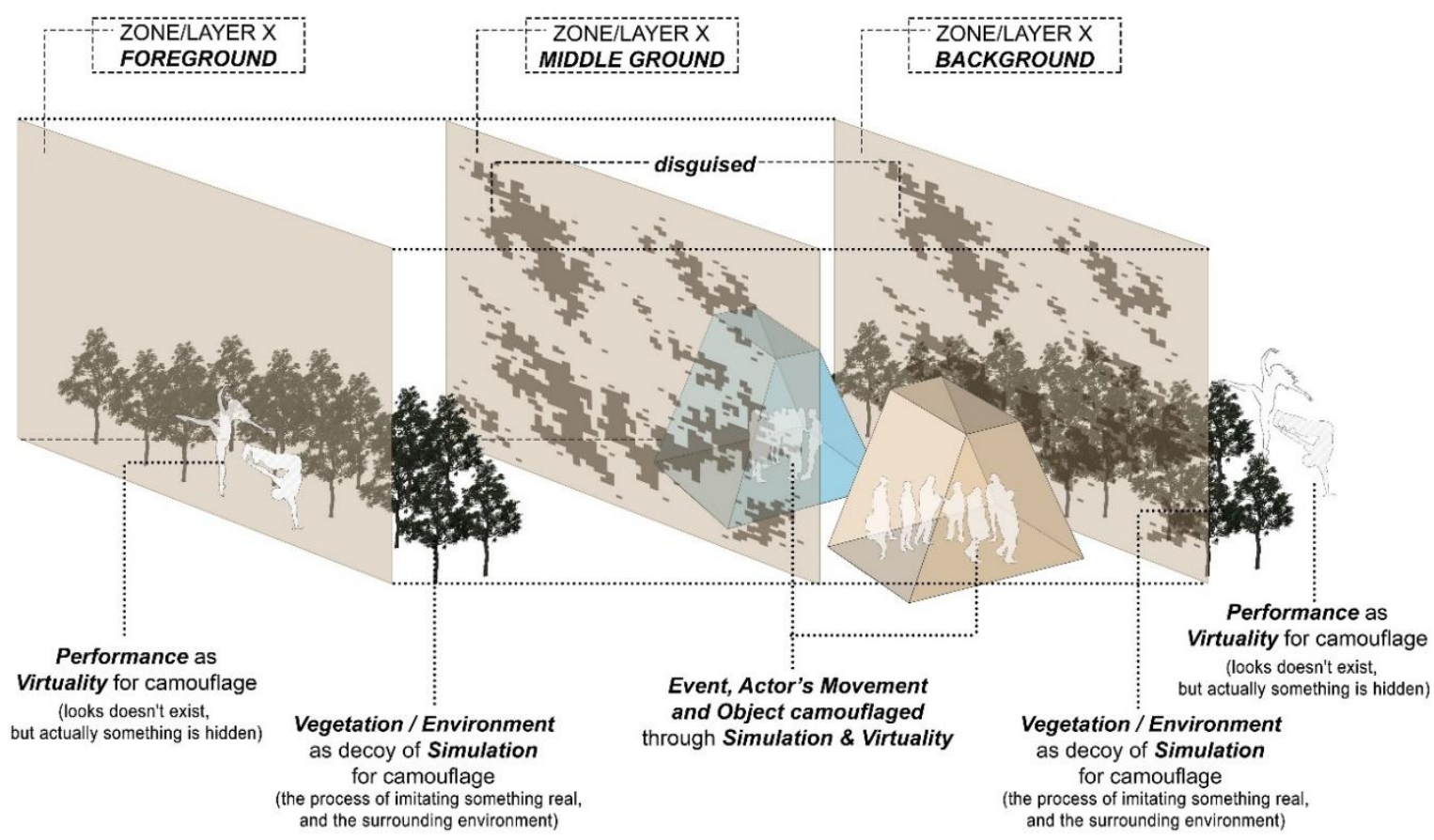

Figure 7. Disappearance Operation

As explained earlier, there are three zones or layers in the camouflage strategy in disappearance operations, i.e., foreground, middle ground, and background (Leach, 2006). In Figure 7, The foreground and the background are a decoy to disguise events, actors' movements, and objects located in the middle ground. The foreground and background can camouflage with performance through virtuality strategies. The virtuality is that looks like doesn't exist but it's still there or hidden. In addition, the foreground can also disguise with vegetation or environment through decoy 
of simulation strategy to camouflage the middle ground, and the simulation is the process of imitating something real, as well as the environment around it. The middle ground has events, actor movements, and objects camouflaged through simulation and virtuality. Based on Allen's previous statement, that montage construction is related to intervals, discontinuity, and surface (Allen, 2009). Thus, virtuality is the surface to disguise something behind it, and simulation is discontinuity to block something behind it.

\section{Reassembly Operations}

Next, reassembly is the final spatial production process, the operation of spatial reconstruction based on montage. Reassembly is done by reassembling the dismantlement and disappearance operations. The reassembly strategy carried out as in the precedent in which Koolhaas emphasized that "...system of assembly analogous to a domino game [...] the Dom-Ino diagram comprises pieces of equipment that resemble the combination of dominos in play [...] the structural method of collage is evident in the production..." (Böck, 2015 , p. 144). The statement can be understood that the reassembly is done by the strategy of combination and collages, consisting of pieces into unity. Reassembly is a final process to create cinematic architecture by emphasizing spatial experience. In the operations of spatial reconstruction, the reassembly is relevant to new space sequences. The sequence needs to reassemble the dismantlement and disappearance operations through combination strategies and collages by trying to recommend possibilities regarding operations of spatial reconstruction based on the montage approach. Reassembly is applied by creating transformation details in each element. This can be seen in the following diagram.

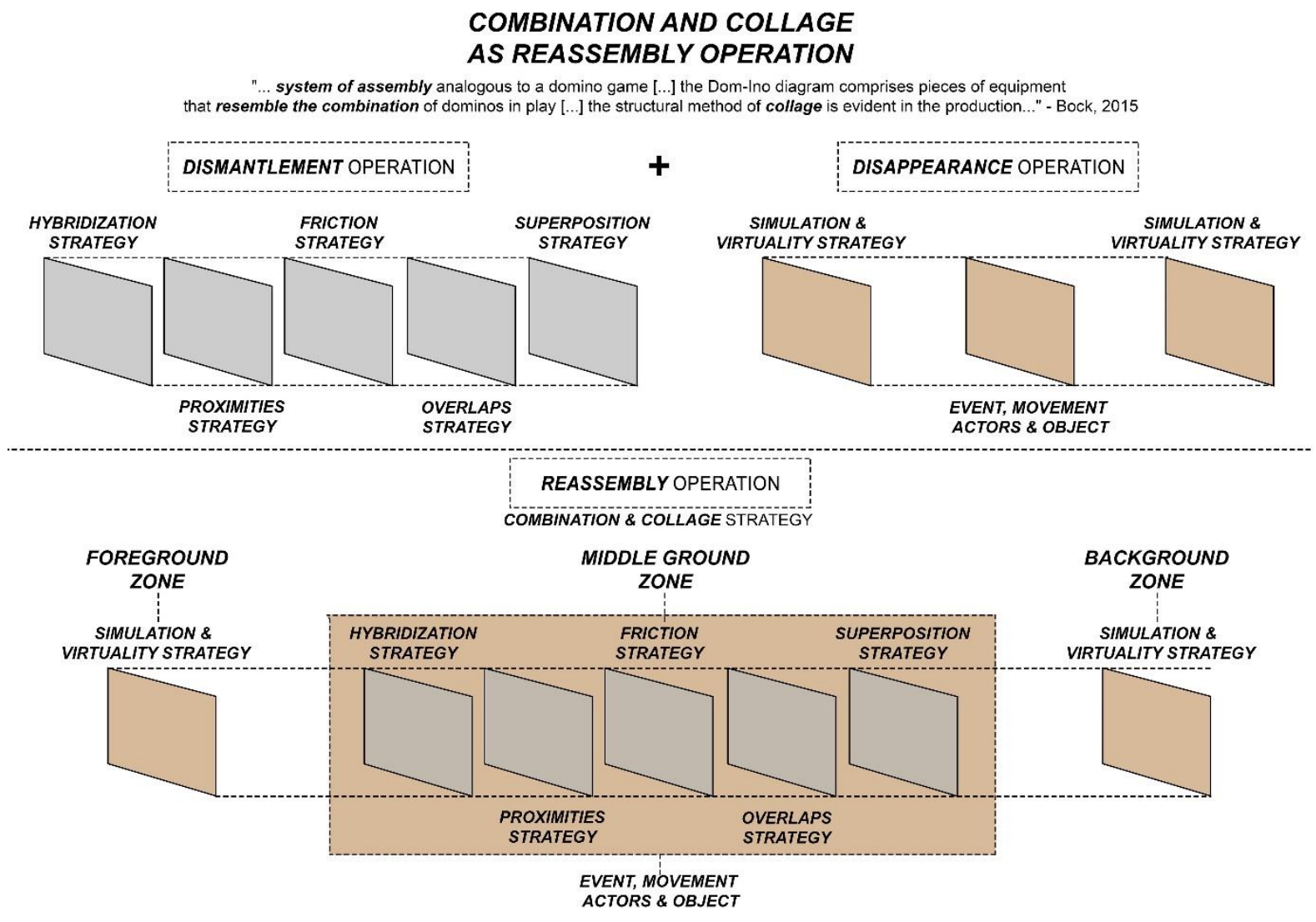

Figure 8. Reassembly Operation

Based on Figure 8, reassembly operations are performed by combining and collaging the dismantlement and disappearance operations. The diagram shows disappearance operations with simulation and virtuality strategies in the foreground and background zones. Meanwhile, dismantlement operations with hybridization, proximities, frictions, overlaps, and superpositions strategies to event, actor movement, and objects in the middle ground. Thus, from pieces into unity to be the basis for designing cinematic architecture based on a montage approach 
through spatial reconstruction to present a sequence of spatial experiences.

Collage assumed into their new context. Collage appropriates ideas from the fields of architectural representation and narrative structure (Lim, 2013). From the statement, it can be understood that the college on the reassembly operation is formed from a representation of the event to be observed and will produce a narrative scenario from a new space experience sequence.

\section{Montage-based Spatial Sequence}

Based on the explanation of previous spatial reconstruction operations, cinematic architecture results from precedent-based synthesis through the operations of dismantlement, disappearance, and reassembly. The dismantlement operation is done with hybridization, proximities, friction, overlaps, and superposition strategies. The disappearance operation is done with strategy simulation and virtuality. The reassembly operation is carried out with combination and collage strategies of the dismantlement and disappearance operations.

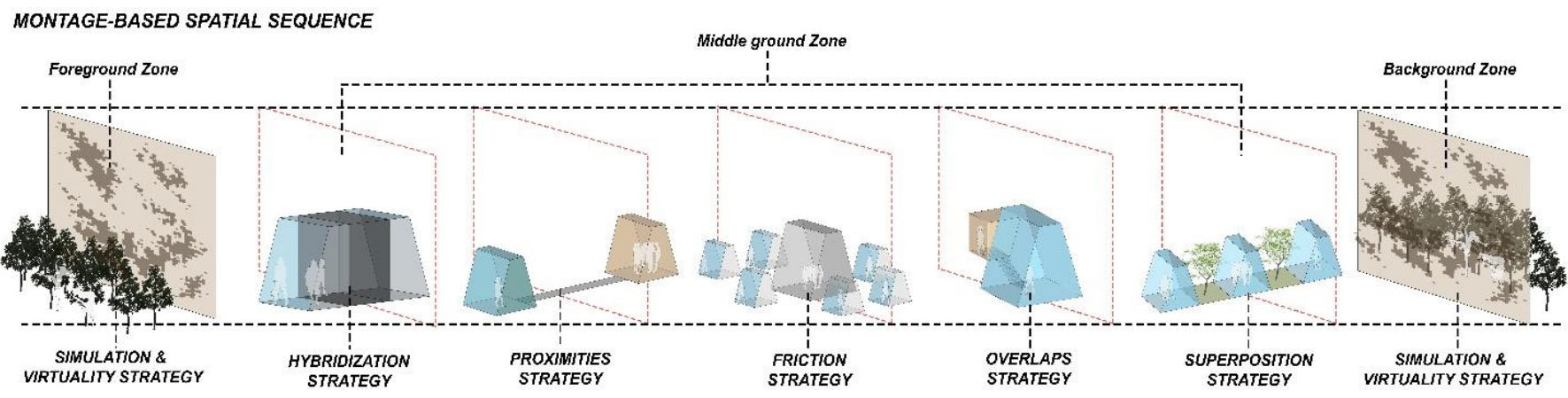

Figure 9. Montage-Based Spatial Sequence

In Figure 9, it can be explained that Foreground and background zone cover the middle ground zone. There are dismantlement strategies in the middle zone, i.e., hybridization, proximities, friction, overlaps, and superposition. The five strategies can change according to the observed event and the spatial needs that will be developed in the design. Meanwhile, in the foreground and background zone, there are virtuality and simulation strategies. Thus, the whole strategy will produce a montage-based spatial sequence. The sequence creates a continuous change of environment and thereby produces a fluid space (Böck, 2015). In this case, to produce sequences that make it easier for relationships between spaces to become more fluid, so users will experience different spatial experiences each time they are in that space. These different spatial experiences can be felt when configuring the strategies in Figure 9.

\section{CONCLUSION}

In this study, the findings obtained are the relationship and impact of montage on designing architectural spaces. Montage exists as an approach in the development of an architectural design that produces and mediates sequences by emphasizing the experience of space. This space experience can be redefined when the existing architectural space is not running properly and requires configuration through sequences and scenarios in operations of spatial reconstruction. In this architectural montage approach, it can be seen that the operations of dismantlement, disappearance, and reassembly are essential as mechanism of developing a new spatial sequence within an architectural design process. The sequence creates a continuous change of environment and thereby produces a fluid space. Using montage as an architectural approach allows designers to produce sequences that generates a more fluid relationships between spaces, so users will experience different spatial experiences each time they are in that space. These different spatial experiences can be felt through configuration of the montage strategies, i.e., simulation, virtuality, hybridization, proximities, friction, overlaps, and superposition strategies. This study expands knowledge regarding design method based on montage that emphasizes reconstruction of spatial experience, as the basis in developing a cinematic architecture. Future exploration may address how such fluidity may also be informed by different qualities of material that construct the performance of montage configuration.

\section{Reference}

Allen, S. (2009). Practice: Architecture, Technique + Representation (2nd ed.). New York: Routledge.

Amidon, J., Rappaport, N., \& Reed, P. (2006). Ken Smith Landscape Architects/Urban Projects: A 
Source Book in Landscape Architecture. Princeton Architectural Press.

Atmodiwirjo, P., \& Yatmo, Y. A. (2021). Urban Interiority: Emerging Cultural and Spatial Practices. Interiority, 4(1), 1-4. https://doi.org/10.7454/in.v4i1.131

Böck, I. (2015). Six canonical projects by Rem Koolhaas: Essays on the History of Ideas. Berlin: jovis Verlag GmbH.

Carranza, L. E. (1994). Le Corbusier and the Problems of Representation. Journal of Architectural Education, 48(2), 70-81. https://doi.org/10.1080/10464883.1994.107346 26

Costanzo, M. (2009). Twenty Years After

(Deconstructivism): An Interview with Bernard Tschumi. Architectural Design, 79, 24-29. https://doi.org/10.1002/ad.804

Dagenhart, R. (1989). Urban architectural theory and the contemporary city: Tschumi and Koolhaas at the Parc de la Villette. Ekistics, 84-92.

Deriu, D. (2007). Montage and modern architecture: Giedion's implicit manifesto. Architectural Theory Review, 12(1), 36-59. https://doi.org/10.1080/13264820701553096

Eisenstein, S. M., Bois, Y.-A., \& Glenny, M. (1989). Montage and Architecture. Assemblage, (10), 111-131. JSTOR. https://doi.org/10.2307/3171145

Frunza, B. (2007). Back in Focus: Cinematic Architecture Beyond Spatial Montage. Miami University, Department of Architecture.

Gutai, M. (2015). Trans Structures: Fluid Architecture and Liquid Engineering. Actar.

Karimah, A., \& Atmodiwirjo, P. (2021). Catalogue drawing: A framing device for design thinking. ARSNET, 1(1).

Koeck, R. (2013). Cine-scapes: Cinematic Spaces in Architecture and Cities. New York: Routledge.

Leach, N. (2006). Camouflage. Cambridge, MA: MIT Press.

Lim, C. (2013). London Short Stories: Drawing Narratives. Architectural Design, 83(5), 102107. https://doi.org/10.1002/ad.1641

Pallasmaa, Juhani. (2007). The Architecture of image: Existential space in cinema. Helsinki: Rakennustieto. /z-wcorg/.

Paramita, K. D. (2021). Weaving theory and practice: Design discourses, exchanges, and processes. ARSNET, 1(1).

Penz, F. (2018). Cinematic Aided Design: An Everyday Life Approach to Architecture. New York: Routledge.

Prince, S., \& Hensley, W. E. (1992). The Kuleshov Effect: Recreating the Classic Experiment.
Cinema Journal, 31(2), 59-75. JSTOR. https://doi.org/10.2307/1225144

Rattenbury, K. (1994). Echo and Narcissus+ Architecture and Film. Architectural Design, (112), 34-37.

Teston, L. (2020). On the Nature of Public Interiority. Interiority, 3(1), 61-82. https://doi.org/10.7454/in.v3i1.72

Till, J. (1996). Architecture in Space, Time. In C. Melhuish (Ed.), Architecture and Anthropology (pp. 12-16). Academy Editions.

Tobe, R. (2017). Film, Architecture and Spatial Imagination. New York: Routledge.

Tschumi, B. (1981). The Manhattan Transcripts: Theoretical Projects. New York: Academy Editions.

Tschumi, B. (1987). Cinegram Folie Le Parc De La Villette. Princeton Architectural Press.

Vidler, A. (2000). Warped Space: Art, Architecture, and Anxiety in Modern Culture. Cambridge: MIT Press. 